\title{
Estudio Histológico del Tubo Digestivo y Aparato Venenoso de Gemmula periscelida (Gastropoda: Turridae)
}

\author{
Histologic Study of Digestive Tract and Venom Apparatus \\ of Gemmula periscelida (Gastropoda: Turridae) \\ Norma Angélica Santibañez Aguascalientes"; Esperanza Ortíz Ordóñez*; \\ Andrés Falcón Alcántara*** \& Edgar P. Heimer de la Cotera**
}

SANTibañez, A. N. A.; ORTíZ, O. E.; FAlCón, A. A. \& HEIMER, C. E. P. Estudio histológico del tubo digestivo y aparato venenoso de Gemmula periscelida (Gastropoda: Turridae). Int. J. Morphol., 31(1):7-14, 2013.

RESUMEN: En el presente trabajo se describe anatómica e histológicamente el tubo digestivo y aparato venenoso de Gemmula periscelida (Gastropoda: Turridae) en ejemplares colectados al Noroeste de la Plataforma Continental Yucateca. Se determinó que el tipo de epitelio que reviste a cada una de las zonas del tubo digestivo (probóscide, esófago anterior, medio y posterior, estómago, glándula digestiva e intestino) y al aparato venenoso, es diferente a lo reportado para otros túrridos; por lo que se infiere el posible mecanismo de alimentación para esta especie.

PALABRAS CLAVE: Tubo digestivo; Aparato venenoso; Turridae; Gemmula periscelida.

\section{INTRODUCCIÓN}

Gemmula periscelida (Dall, 1889) pertenece a la familia Turridae, siendo la más diversa (aproximadamente 4000 especies) de la superfamilia Conoidea (Bouchet \& Rocroi, 2005; Bouchet et al., 2009) de la familia Turridae la más diversa (más de 4000 especies), se caracteriza por presentar una apomorfía: un aparato venenoso, que es usado principalmente para paralizar y capturar a sus presas, aunque algunos lo usan para escapar o defenderse de otros depredadores y posiblemente para disuadirse de competidores (Aguilar et al., 2009). Las diferencias anatómicas e histológicas de estructuras, como: probóscide, masa bucal, aparato radular y venenoso, glándulas accesorias salivales, glándulas salivales, labios bucales y esófago anterior; reflejan distintos mecanismos de alimentación y de dieta, como es el caso de los túrridos que son organismos depredadores de anélidos (errantes o sedentarios), sipuncúlidos y nemertinos (Shimek, 1975; Taylor et al., 1980; Shimek \& Kohn, 1981; Maes, 1983; Miller, 1989; Kantor, 1990; Taylor et al., 1993; Taylor, 1994; Kantor \& Taylor, 2000; García-López et al., 2007; Heralde III et al., 2010). Menos del 10\% de los túrridos han sido estudiados (Kantor et al., 2008), debido a varios factores: la gran similitud morfológica entre especies; el que habiten en aguas profundas (50-500 m); que sean de tamaños pequeños a medianos (3-50 mm en promedio); que su comportamiento sea nocturno y sus hábitos enterradores (Tucker, 2004; Heralde III et al., 2010). En la actualidad, para G. periscelida solo se han reportado dos trabajos, uno referente a la caracterización peptídica de los conductos de veneno, realizado por LópezVera et al. (2004), y otro elaborado por Tirado (2008), quién describió histológicamente el aparato radular y venenoso.

\section{MATERIAL Y MÉTODO}

Los ejemplares fueron colectados en dos sitios al Noroeste de la Plataforma Continental Yucateca $\left(23^{\circ} 10^{\prime} 25^{\prime \prime} \mathrm{La}-\right.$

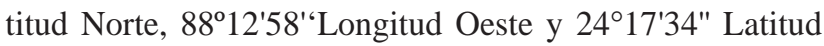
Norte, $89^{\circ} 47^{\prime} 41^{\prime \prime}$ Longitud Oeste) realizándose arrastres a diferentes profundidades (200 a 456 metros). Los ejemplare se fijaron en una solución de formol al 10\%. El aparato venenoso y el tracto digestivo se deshidrataron con cambios de etanol, de menor a mayor concentración, posteriormente se transparentó en una mezcla 50:50 de alcohol absoluto-xileno y dos cambios en xilol; fueron incluidos en Paraplast ${ }^{\circledR}$. Se realizaron cortes seriados ( 7 y $5 \mu \mathrm{m}$ para el tracto digestivo y el aparato venenoso respectivamente) y fueron teñidos con las técnicas de Hematoxilina-Eosina y Tricrómica de Masson, finalmente se obtuvieron microfotografías en un fotomicroscopio Nikon eclipse 80i.

\footnotetext{
* Laboratorio de Histología, Instituto Politécnico Nacional, Escuela Nacional de Ciencias Biológicas 11340, México.

** Laboratorio de Neurofarmacología, Instituto de Neurobiología, Universidad Nacional Autónoma de México, Querétaro, 76230, México.
} 


\section{RESULTADOS}

Probóscide. Se localiza en la parte anterior del tubo digestivo, es una prolongación del tubo bucal (Fig. 1A). Constituida por un epitelio cilíndrico simple ciliado, con pliegues bajos y delgados que obliteran la luz del conducto. Estos están rodeados por tejido conectivo laxo seguido, de fibras musculares circulares y longitudinales (Fig. 1B, 1C).

Boca. Está localizada en la base de la probóscide; presenta pliegues altos y bajos revestidos por un epitelio cilíndrico simple cuticularizado, las células del epitelio en su parte apical presentan pequeñas granulaciones acidófilas; los pliegues descansan sobre una lamina propia, por debajo de ésta,
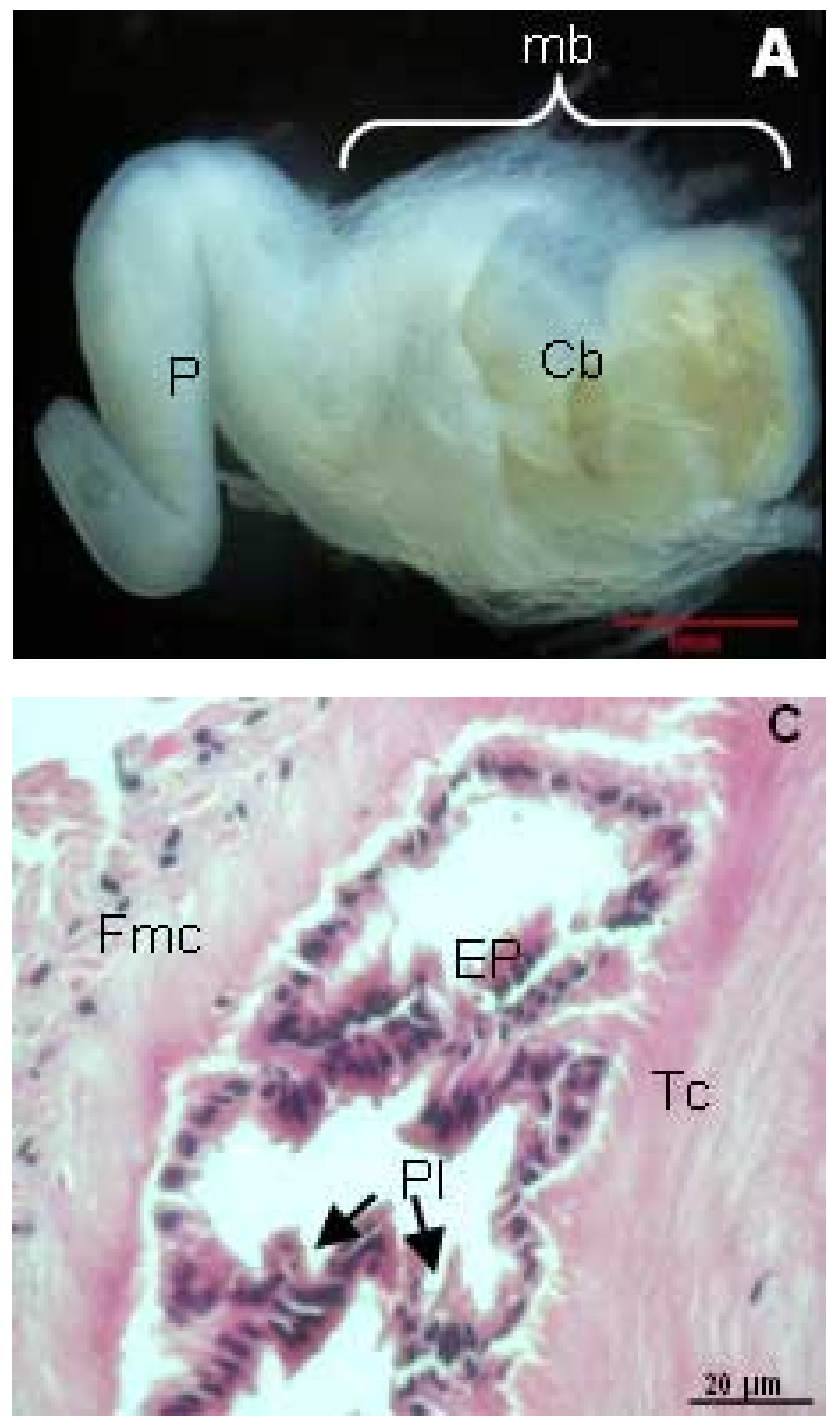

se encuentran abundantes fibras de colágena y fibras musculares, tanto longitudinales como circulares (Fig. 1B, 1D).

Cavidad bucal. Está dividida en dos cámaras, una proximal, donde se encuentra el aparato radular (Fig. 2A), en su parte inferior se observa un epitelio similar al de la boca, pero sin pliegues; hacia la parte superior se encuentran dos dientes marginales esclerotizados, situados entre dos cartílagos del odontóforo (Fig. 2B); y otra distal, que corresponde al esófago anterior (Fig. 2A), éste presenta un epitelio cilíndrico simple cuticularizado que descansa sobre una membrana basal, formando pliegues altos y bajos, tienen una lámina propia, de tejido conectivo laxo; en la parte más externa del esófago se observan fibras musculares circulares. Las células epiteliales presentan granulaciones acidófilas, similar al de la boca. (Figs. 2C, 2D).
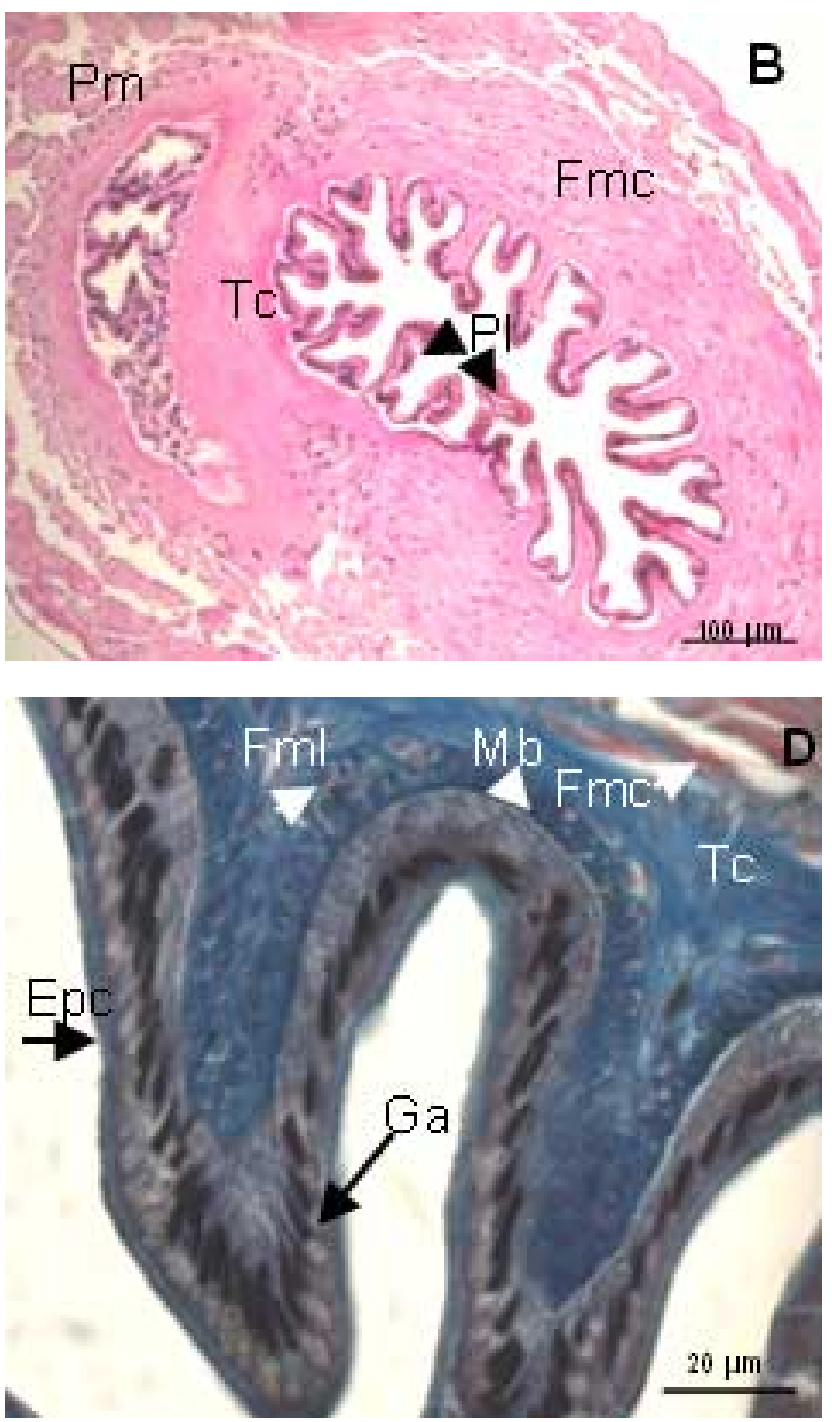

Fig. 1. Probóscide y boca. A. Anatomía de la parte anterior del tubo digestivo; B. Panorámica de probóscide y boca; C. Acercamiento de la probóscide; D. Aumento de los pliegues de la boca; Cb. Cavidad bucal; Ga. Granulaciones acidófilas; EP. Epitelio cilíndrico simple ciliado; Epc. Epitelio cilíndrico simple cuticularizado; mb. Masa bucal; Mb. Membrana basal; Fmc. Fibras musculares circulares; Fml. Fibras musculares longitudinales; P. Probóscide; Pl. Pliegues; Pm. paquetes musculares; Tc. Tejido conectivo laxo. 

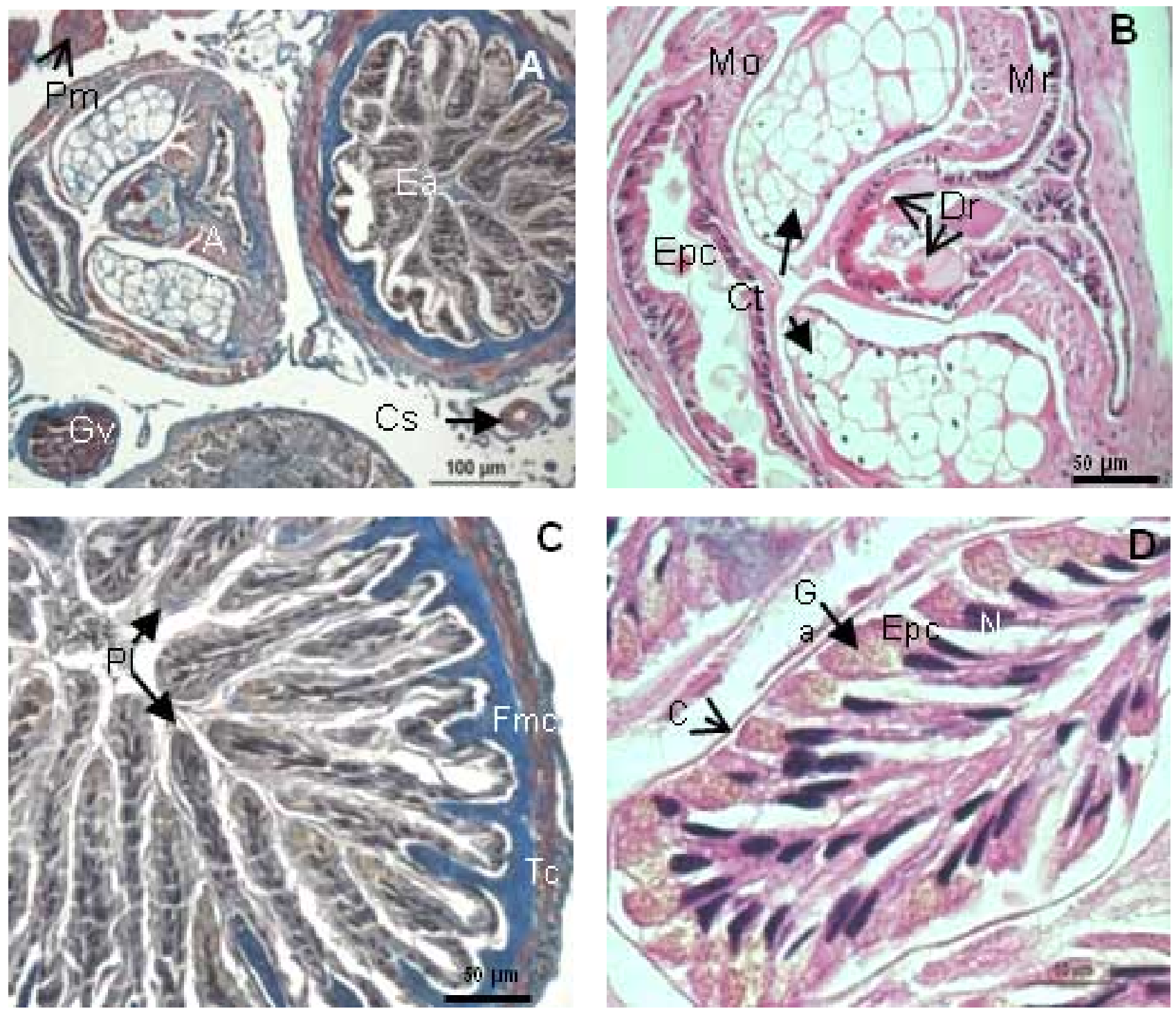

Fig. 2. Cavidad bucal. A. Aparato radular (proximal) y esófago anterior (distal); B. Aparato radular; C. Esófago anterior; D. Granulaciones acidófilas; Ar. Aparato radular; C. Cutícula; Cs. Conductos salivales; Ct. Cartílago; Dr. Dientes radulares; Ea. Esófago anterior; Fmc. Fibras musculares circulares; Ga. Granulaciones acidófilas; Gv. Glándula de veneno; Epc. Epitelio cilíndrico simple cuticularizado; Mo. Músculos protractores y retractores del odontóforo; Mr. Músculos protractores y retractores de la rádula; N. Núcleo; Pm. Paquetes musculares.

Glándula de veneno. El conducto venenoso está muy plegado (Fig. 3A), pasa a través del anillo nervioso y converge en la cavidad bucal, a un costado de la apertura del saco radular (Fig. 2A). Presenta una capa gruesa de fibras de colágena que rodea a las células secretoras observándose que los gránulos de veneno ocupan la mayor parte de éstas, siendo los núcleos basales (Fig. 3B).

Bulbo venenoso. En la parte distal de la glándula de veneno, se encuentra un bulbo muscular transparente con forma elíptica (Fig. 3A). El bulbo muscular está formado por capas alternas de fibras circulares y longitudinales, separadas por una fina capa de fibras de colágena. En la zona central del bulbo muscular se encuentra un epitelio de revestimiento (Fig. 3C).
Esófago. Está constituido por dos regiones una corresponde al esófago medio, que es un tubo recto que conecta la parte anterior del sistema digestivo con la posterior del mismo (Fig. 4A). Está recubierto por un epitelio cilíndrico simple ciliado, con granulaciones acidófilas, el epitelio forma pliegues largos que descansan sobre una membrana basal, a continuación se encuentra la lámina propia seguida de escasas fibras musculares entre abundantes fibras de colágena (Fig. 4B). En la última región el epitelio es el mismo a la zona anterior, sin embargo, las granulaciones acidófilas son menos abundantes y los pliegues son más anchos y de diferentes tamaños que descansan sobre una membrana basal muy fina, enseguida está la lámina propia de tejido conectivo laxo (Fig. 4C). 

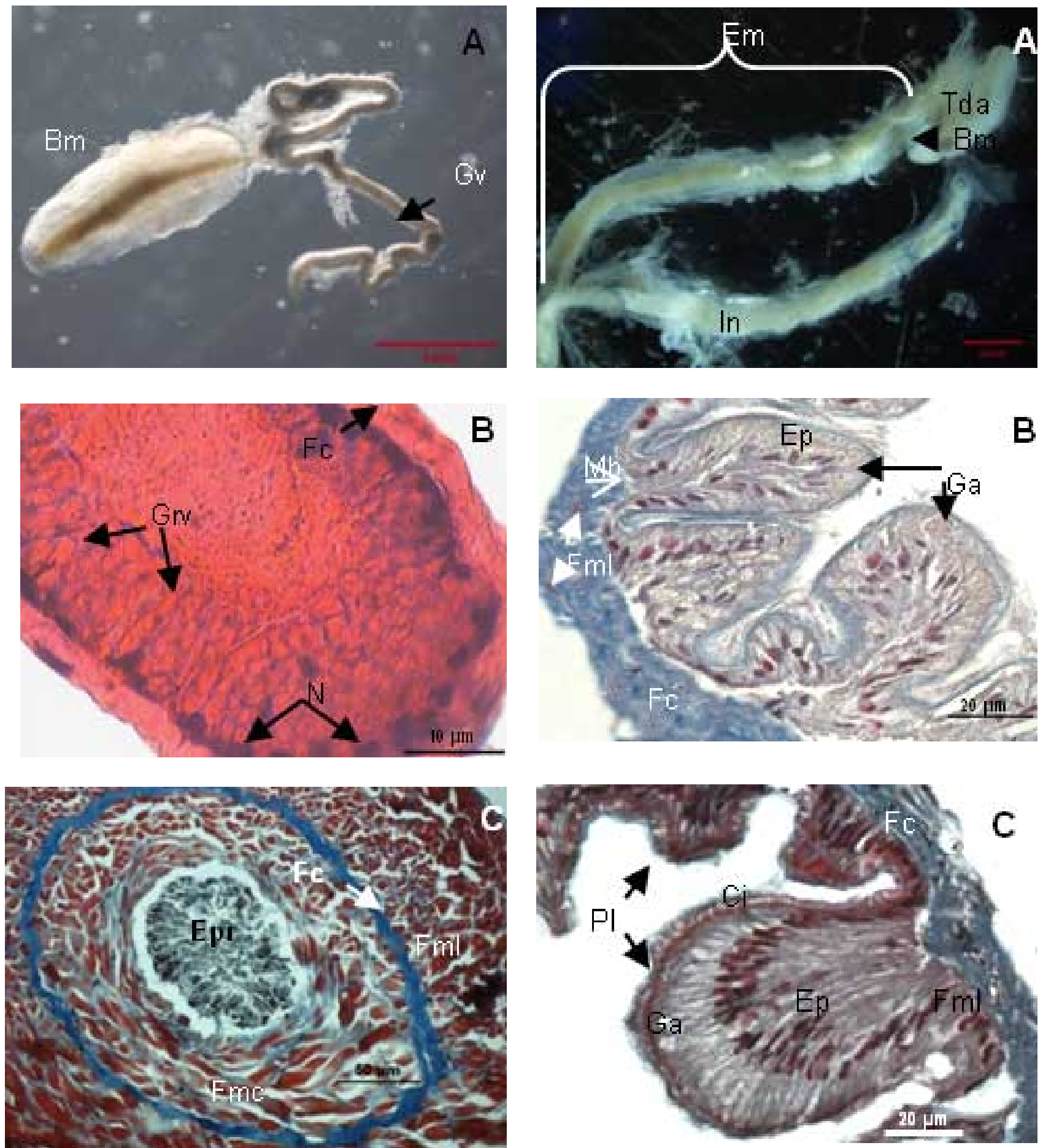

Fig. 3. Aparato venenoso. A. Anatomía del aparato venenoso; B. Glándula de veneno; C. Bulbo muscular; Bm, Bulbo muscular; Epr. Epitelio de revestimiento; Fc. Fibras colágenas; Fmc. Fibras musculares circulares; Fml. Fibras musculares longitdinales; Grv. Gránulos de veneno; Gv. Glándula de veneno; N. Núcleo.

Fig. 4. Regiones del esófago. A. Anatomía del esófago; B. Esófago medio; C. Esófago posterior; Ci. Cilios; Em. Esófago medio; Ep. Epitelio cilíndrico simple ciliado; Fc. Fibras de colágeno; Fml. Fibras musculares longitudinales; Ga. Granulaciones acidófilas; In. Intestino; Mb. membrana basal; Pl. Pliegues. Tda. Tracto digestivo anterior. 
Estómago. Tiene forma de saco con un surco ventral, debajo de éste se encuentra parte de la glándula digestiva y en la parte anterior se localiza el esófago y el intestino (Fig. 5A). El estómago se divide histológicamente en tres regiones, diferenciadas por la forma de los pliegues que presenta, y por la abundancia de las granulaciones acidófilas, no obstante, en estas tres zonas se presenta un epitelio cilíndrico simple ciliado. En la primera región el epitelio está dispuesto en pliegues uniformes bajos y anchos muy juntos (Figs. 5B); en la segunda región los pliegues son irregulares unos más largos que otros, las granulaciones acidófilas son abundantes ocupando la mayor parte de la célula (Fig. 5C). En la tercera región los pliegues son mucho más anchos que en las dos zonas anteriores, y las granulaciones acidófilas son menos evidentes (Fig. 5D).
Glándula digestiva. Está formada por adenómeros túbuloacinosos, en donde se presentan dos tipos de células con secreción granular: proteica y glicoproteica (Fig. 6A).

Intestino. Se divide en cuatro regiones: en las dos primeras regiones el epitelio es cilíndrico simple con chapa estriada contiene granulaciones acidófilas, sin embargo, en la primera región se forman abundantes pliegues bajos y estrechos (Fig. 6B, 6C); en la tercera región el epitelio continúa bajando de altura hasta observarse cilíndrico bajo simple con chapa estriada (fig. 5D). En la última región el epitelio es cilíndrico simple ciliado y forma pliegues bajos irregulares, rodeados por una delgada capa de tejido conectivo laxo (Fig. 6D).
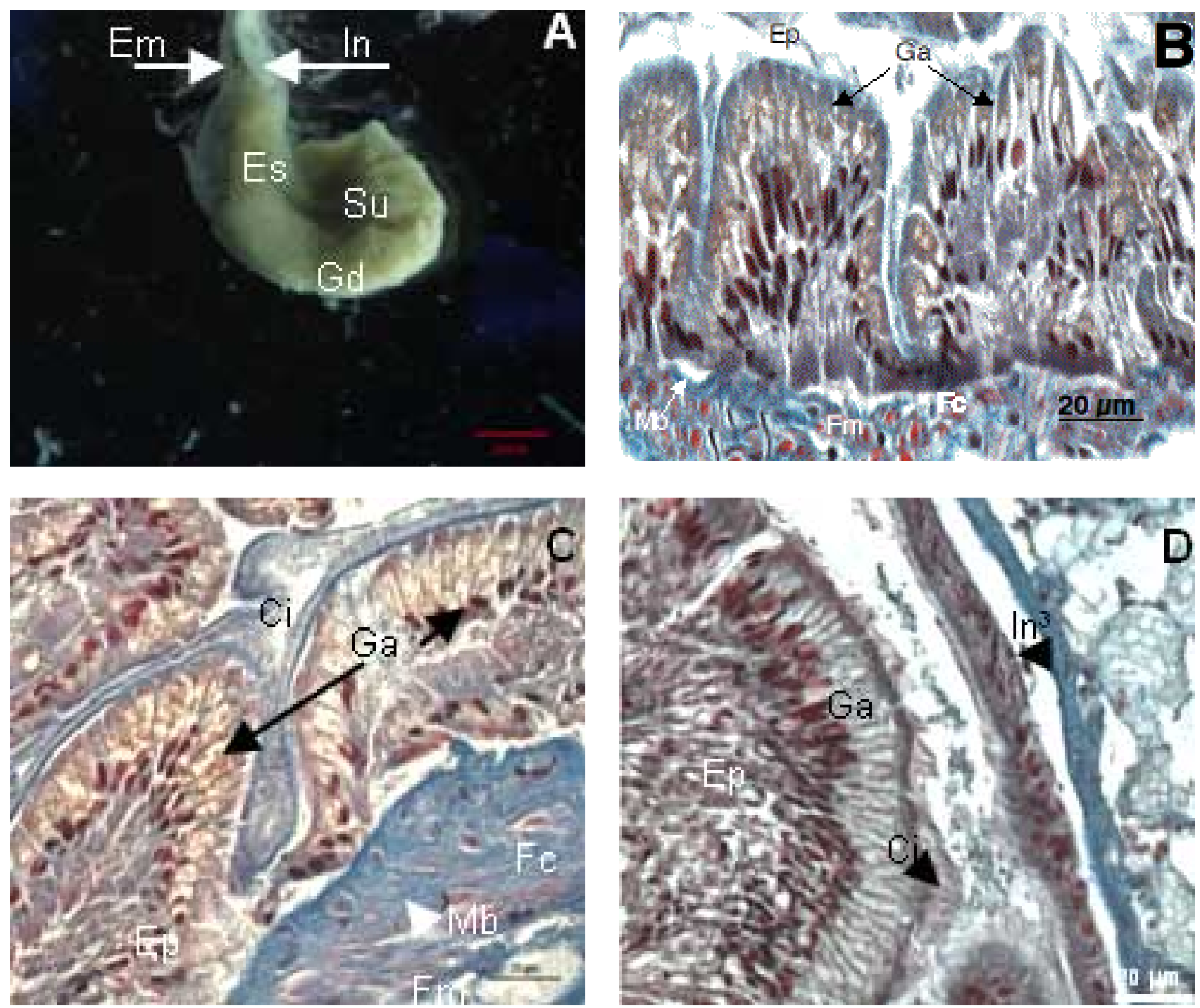

Fig. 5. Estómago. A. Anatomía del estómago; B. Estómago, primera región; C. Estómago, segunda región; D. Estómago, tercera región; Ci. Cilios; Em. Esófago medio; Ep. Epitelio cilíndrico simple ciliado; Es. Estómago; Fc. Fibras de colágeno; Fm Fibras musculares; Ga. Granulaciones acidófilas; In. Intestino; $\mathrm{In}^{3}$. Intestino, tercera región; Gd. Glándula digestiva; Mb. Membrana basal; Su. Surco. 

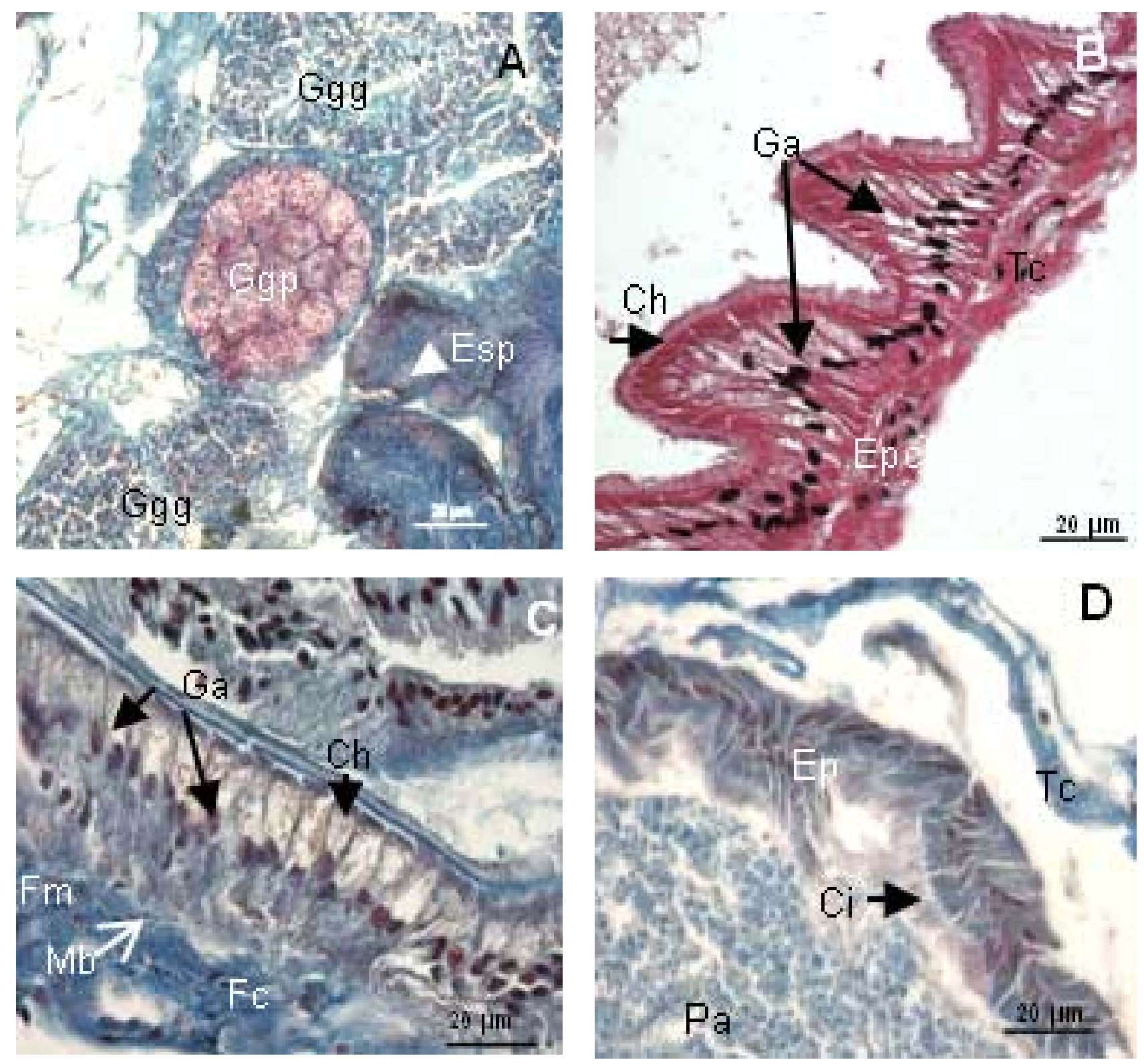

Fig. 6. Tracto digestivo posterior. A. Glándula digestiva; B. Intestino, primera región; C. Intestino, segunda región; D. Intestino, cuarta región; Ci. Cilios; Ch. Chapa estriada; Ep. Epitelio cilíndrico simple ciliado; Epch. Epitelio cilíndrico simple con chapa estriada; Esp. Espermatozoides; Fc. Fibras de colágeno; Fm. Fibras musculares; Ga. Granulaciones acidófilas; Ggg. Secreción granular glicoproteica; Ggp. Secreción granular proteica; Mb. membrana basal; Pa. Partículas de alimento; Tc. Tejido conectivo laxo.

\section{DISCUSIÓN}

La radiación adaptativa en Turridae está asociada con una gran variedad de especializaciones morfológicas y fisiológicas, las cuales facilitan la detección, captura y digestión de la presa (Taylor et al., 1993). Las observaciones histológicas realizadas en este trabajo, infieren que el mecanismo alimentario de Gemmula periscelida es diferente al de G. deshayesii y G. speciosa, ambas especies del Indo-
Pacífico. Aunque estas tres especies tienen una probóscide intraembólica, G. periscelida no presenta un esfínter, a diferencia de G. deshayesii y G. speciosa. Miller (1989), Taylor (1994) y Heralde III et al. (2010) mencionan que este esfínter se encuentra en la punta de la probóscide, en la mayoría de los túrridos, para sostener el diente marginal dúplex, y así poder cazar y envenenar a sus presas. El mecanismo 
alimentario de $G$. periscelida comenzaría por detectar a la presa a través de los quimiorreceptores que se localizan en el osfradio, la probóscide se extendería debido al incremento en la presión hidrostática ejercida en el hemocele ocasionando la contracción de las fibras musculares para capturar a su presa y transportarla hacia la boca, en donde el epitelio cilíndrico simple cuticularizado sirve de protección, y las secreciones de las granulaciones acidófilas son liberadas a través de poros localizados sobre la superficie de la cutícula, iniciando la degradación de la epidermis de la presa, como lo describen Fretter \& Graham (1994) para otras especies de prosobranquios. La contracción de los músculos longitudinales y circulares de la boca seguirían moviendo a la presa hacia la cavidad bucal, así, los dientes dúplex raspan, perforan y envenenan a la presa, como sugieren Kantor \& Taylor (2000), que los dientes están unidos a la membrana radular y el veneno es transportado por el surco que se forma en el diente, así el movimiento de los dientes es debido al sistema de músculos protractores y retractores de la rádula y del odontóforo. La producción de veneno es uniforme a lo largo del conducto glandular, porque se observó que la distribución de las células secretoras es similar.

La caracterización bioquímica de turritoxinas, revelan que las formas de Gemmula del Atlántico y del este del Pacífico no pertenecen a un mismo clado que a las especies del Indo-Pacífico, siendo homologa la secuencia de toxinas de veneno para G. diomedea, G. speciosa, G. sogodensis y G. kieneri, presentan presas en común, poliquetos sedentarios de la familia Terebellidae (Heralde III et al., 2010). De acuerdo a lo anterior, la familia presa blanco de G. periscelida es diferente, debido a la novedosa clase estructural de toxinas reportado por López-Vera et al. (2004).

La presencia de fibras musculares circulares y longitudinales separadas por una fina capa de fibras de colágena, observadas en el bulbo muscular, demuestra que su principal función es la traslocación y liberación del veneno, como lo reportan Safavi-Hemami et al. (2010). La presencia de las granulaciones acidófilas en las tres regiones del esófago, indica la continuidad de la degradación del alimento, debido a la acción enzimática proteica y salival, está última proveniente de los conductos de las glándulas salivales, en otras especies de Conoidea las glándulas salivales contribuyen a la producción del veneno, de manera que aumentan la eficiencia de envenenamiento durante la captura de sus presas, eliminan los desechos proteolíticamente y lubrican los dientes radulares (Biggs et al.,2008).

El alimento es conducido hacia el estómago por la acción de los cilios y por los movimientos peristálticos de las paredes esofágicas. Las tres regiones del estómago nos indica diferentes procesos digestivos, en la primera y segunda región, debido a la abundancia de granulaciones acidófilas, se realiza la transformación del alimento en partículas más pequeñas y en la tercera región en donde hay una disminución de estas granulaciones, pudiera indicarnos que esta zona es la transición, para que el alimento ya parcialmente digerido pase a la glándula digestiva, así las células con gránulos de secreción proteica realizan la digestión total y pueda ser absorbido por las células intestinales.

Se observaron cuatro regiones en el intestino de $G$. periscelida, las tres primeras, tienen un epitelio cilíndrico simple con chapa estriada, con el cual absorben los nutrientes, está absorción se llevaría a diferentes grados debido al arreglo del epitelio, ya que en la primera región sería mayor la absorción del alimento puesto que se observan pliegues bajos y anchos que le dan mayor superficie de absorción; en cambio en la segunda y tercera región el epitelio no forma pliegues y se va haciendo más bajo. La presencia de las granulaciones acidófilas en este nivel del tracto digestivo serían requeridas para el embalaje de los productos de desechos; este material es eliminado por la acción de las corrientes ciliares presentes en la cuarta región del intestino.

\section{AGRADECIMIENTOS.}

Se agradece a las profesoras del Laboratorio de Histología del Departamento de Morfología de la ENCB del I.P.N. y al Laboratorio de Neurofarmacología del Instituto de Neurobiología de la UNAM campus Juriquilla, el cual nos proporcionó los ejemplares para la realización de este trabajo.

SANTIbAÑEZ, A. N. A.; ORTíZ, O. E.; FALCÓN, A. A. \& HEIMER, C. E. P. Histologic study of digestive tract and venom apparatus of Gemmula periscelida (Gastropoda: Turridae). Int. J. Morphol., 31(1):7-14, 2013.

SUMMARY: In this paper we realized anatomical and histologically description of the digestive tract and venom apparatus of Gemmula periscelida (Gastropoda: Turridae) specimens collected northwest of the Yucatan Shelf. Results of analysis show that there are differences in the type of epithelium coating each of the areas of the digestive tract (proboscis, anterior, middle and posterior esophagus, stomach, digestive gland and intestine) and of a venom apparatus with respect to that reported for other turrid snails. This suggests the possible feeding mechanism for this species.

KEYS WORD: Digestive tract; Venom apparatus; Turridae; Gemmula periscelida. 


\section{REFERENCIAS BIBLIOGRÁFICAS}

Aguilar, M. B.; Chan R. R.; Falcón A.A.; Olivera B. M. \& Heimer E. C. Peptide pal9a from the venom of the turrid snail Polystira albida from the Gulf of Mexico: purification, characterization, and comparison with P-conotoxin-like (framework IX) conoidean peptides. Peptides, 30:467-76, 2009.

Biggs, J. S.; Olivera, B. M. \& Kantor, Y. I. a-Conopeptides specifically expressed in the salivary gland of Conus pulicarius. Toxicon, 52 (1):101-5, 2008.

Bouchet, P. \& Rocroi, J-P. Classification and nomenclator of gastropod families. Malacologia, 47:1-397, 2005.

Bouchet, P.; Lozouet, P. \& Sysoev, A. An inordinate fondness for turrids. Deep-Sea Research II, 56:1724-31, 2009.

Dall, W.H. Report on the Mollusca part II: Gastropoda and Scaphopoda. Bulletin of the Museum of Comparative Zoology, 18:74-5, 1889.

Fretter, V. \& Graham, A. British Prosobranch Molluscs. Their functional anatomy and ecology. The Ray Society, London, 1994.

García-López, A.; Uría-Galicia, E. A. \& Ortíz-Ordóñez, E. Estudio histológico de boca, esófago, estómago e intestino de Polystira albida (Gastropoda: Turridae). Int. J. Morphol., 25 (4):767-74, 2007.

Heralde III F. M.; kantor, Y. I.; Astilla, Q. M. A.; Lluisma, A. O.; Geronimo, R.; Aliño, P. M.; Watkins, M.; Corneli, P. S.; Olivera, B. M.; Santos, A. \& Concepcion, G. P. The IndoPacific Gemmula species in the subfamily Turrinae: aspects of field distribution, molecular phylogeny, radular anatomy and feeding ecology. Philippine Science Letters, 3:21-34, 2010 .

Kantor, Y. I. Anatomical basis for the origin and evolution of the toxoglossan mode of feeding. Malacologia, 32 (1): 3-18, 1990.

Kantor, Y. I. \& Taylor, J.D. Formation of marginal radular teeth in Conoidea (Neogastropoda) and the evolution of the hypodermic envenomation mechanism. J. Zoological Society of London, 252: 251-62, 2000.

Kantor, Y. I.; Puillandre, N.; Olivera, B.M. \& Bouchet, P. Morphological Proxies for Taxonomic Decision in Turrids (Mollusca, Neogastropoda): a Test of the Value of Shell and Radula Characters Using Molecular Data. Zoological science, 25:1156-70, 2008.

López-Vera, E.; Heimer, E. C.; Maillo, M.; Riesgo-Escovar, J. R.; Olivera, B. M. \& Aguilar, M. B. A novel structural class of toxins: the methionine-rich peptides form the venoms of turrid marine snails (Mollusca, Conoidea). Toxicon, 43:365-74, 2004.
Maes, V.O. Observations on the systematics and biology of a turrid gastropod assemblage in the British Virgin Islands. Bulletin of Marine of Science, 33:305-35, 1983.

Miller, J. A. The Toxoglossan Proboscis: Structure and Function. J. Molluscan Studies, 55 (2):167-81, 1989.

Safavi-Hemami, H., Young, N. D., Williamson, N. A. \& Purcell, A. W. Proteomic Interrogation of Venom Delivery in Marine Cone Snails: Novel Insights into the Role of the Venom Bulb. J. of Proteome Research, 9:5610-9, 2010.

Shimek, R. L. The morphology of the buccal apparatus of Oenopota levidensis (Gastropoda, Turridae). Zeitschrift für Morphologie de Tiere, 80:59-96, 1975.

Shimek, R. L. \& Kohn, A. J. Functional morphology and evolution of the Toxoglossan radula. Malacologia, 20 (2): 423-38, 1981.

Taylor, J.D.; Morris, N.J. \& Taylor, C.N. Food specialization and the evolution of predatory prosobranch gastropods. Palaeontology, 23:375-409, 1980.

Taylor, J. D.; Kantor, Y. I. \& Sysoev, A. V. Foregut anatomy, feeding mechanisms, relationships and classification of the Conoidea (= Toxoglossa) (Gastropoda). Bulletin of the British Museum (Natural History), Zoology, 59 (2):125-70, 1993.

Taylor, J.D. Foregut anatomy of the larger species of Turrinae, Clavatulinae and Crassispirinae (Gastropoda: Conoidea) from Hong Kong. In: Morton, B. (Ed.). Proceeedings of the Third International Workshop on the Malacofauna of Hong Kong and Southern China. Hong Kong University Press, 1994.pp. 185-213.

Tirado, T. Comparación histológica del aparato venenoso de Gemmula periscelida y Polystira albida. (Turridae: Neogastropoda). Tesis de licenciatura, Universidad Autónoma de Querétaro, Querétaro, México, 2008.

Tucker, J. K. Catalog of recent and fossil turrids (Mollusca: Gastropoda). Zootaxa, 682, 1-1295, 2004.

Dirección para correspondencia:

Norma Angélica Santibañez Aguascalientes

Laboratorio de Histología

Instituto Politécnico Nacional

Escuela Nacional de Ciencias Biológicas 11340

México - DF

MÉXICO

Email: norma_bio@hotmail.com

Recibido : 22-05-2012

Aceptado: 17-12-2012 